\title{
Interaksi Komunikasi Dalam Dialog Drama Performance Class Mahasiswa Jurusan Bahasa Inggris STBA IEC Jakarta (Suatu Kajian Etnografi Komunikasi)
}

\author{
Sri Arfani \\ ABA BSI Jakarta \\ Jl. Salemba Tengah No. 45. Jakarta Pusat \\ Email: sri.saf@bsi.ac.id
}

\begin{abstract}
This study is a study of ethnography communication. The purpose of this research is to know the phenomenon of communication interaction in performance drama class. The pattern of communication is in discourse analysis through approach of ethnography of communication. The method of this study was descriptive content analysis. The procedure of data analysis and interpretation adapted pattern SPEAKING GRID model made by HYMES. The data were taken from the scenario of drama dialog in STIBA IEC Jakarta class. The findings in this study are the clarity of the content of the conversation that has a pattern in accordance with the requirements of the process. The topic and purpose of patterned conversation arose. It was raised a new topic. The process of new topic was finding from the act sequence. The results of the conversations was finding in the end of the dialog namely: the dialog was need and provide information, the dialog was receive information, the dialog was having positive responses, the dialog was asking questions and providing answers. Based of the results of the dialog of speaking in the drama performance has change of the diferent message and contents.
\end{abstract}

Keywords: Communication interaction, Dialog SPEAKING GRID, ethnography communication .

\section{PENDAHULUAN}

1. Latar belakang

Ketrampilan bermain drama adalah retifitas seseorang untuk menajamkan bentuk komunikasi dengan realitas melalui” seni berpura puraan”. Bentuk-bentuk ekspresi yang diharuskan sesuai dengan naskah, seyogyanya bukanlah diri sendiri, melainkan menjadi orang lain. Adanya naskah menuntut actor untuk menyampaikannya dengan dialog dan cara yang berbeda pula di hadapan penonton. Apabila seorang actor dapat menjalani proses latihan itu dengan baik, maka kemampuan untuk memunculkan keberanian dan memahami persoalan-persoalan dala menghadapi penonton dapat teratasi secara lebih cermat. Hal tersebut adalah salah satu keterampilan yang secara langsung dapat diimplementasikan dalam bermain drama yakni keterampilan berbicara atau berkomunikasi yang membutuhkan keberanian mental menyampaikan gagasan di depan banyak orang.

Unsur komunikasi yang tidak kalah penting adalah percakapan. Melalui percakapan, komunikasi yang dilakukan dapat dinilai sebagai komunikasi yang biasa-biasa saja atau yang tergolong tingkat tinggi. Percakapan adalah sebuah rangkaian interaksi dengan awal dan akhir dengan beberapa maksud dan tujuan.

Dalam proses belajar mengajar yang dilalukan di kelas, Tenaga pengajar menggunakan bermacam- macam metode, dan salah satu metode pembelajaran yang digunakan dalam kelas drama adalah performance atau pertunjukkan. Keberadaan performance menjadi salah satu jenis komunikasi di kelas yanag bisa berfungsi sebagai sarana untuk menyampaikan dan berbagi informasi tentang pengetahuan yang berhubungan dengan topik pembahasan kepada mahasiswa lain.

Performance/pertunjukan melalui dialog dalam drama sebagai salah satu proses interaksi komunikasi dapat membangun wacana baru yang berhubungan dengan topik pembicaraan ataupun dalam mencari solusi permasalahan. Selama proses performance ini berlangsung, terbangun langkahlangkah pengembangan topik mulai dari pembukaan sampai penutupan. Performance dalam drama memberikan kesempatan kepada mahasiswa untuk berekspresi dan kreatif dalam mengungkapkan bakat seni yang mereka miliki.

Interaksi komunikasi yang terbentuk dalam kelompok performance melalui drama akan membantu mahasiswa dalam memahami materi yang dipelajarinya seperti mata kuliah sastra. Dalam hal ini, konteks akan berperan dalam proses membangun pemahaman topik. Mahasiswa dapat mengetahui siapa yang berbicara dan apa yang sedang dibicarakan, Sehingga terbangun suatu pola komunikasi yang didasarkan atas budaya dan perilaku dari setiap orang yang berbicara. Perilaku 
berbahasa dalam proses komunikasi seperti yang terjadi dalam dialog drama dapat dikaji melalui etnografi komunikasi. Etnografi komunikasi adalah pendekatan terhadap wacana yang berdasarkan pada antropologi dan linguistik. Namun, pendekatan tersebut tidak hanya fokus pada perilaku komunikatif, tetapi dibangun juga atas teori dan metodologi untuk menemukan variasi bentuk dan fungsi yang ada dalam komunikasi. Dalam hal ini tentunya, variasi bentuk dan fungsi komunikasi dalam proses dialog.

Selanjutnya, Etnografi komunikasi bukan merupakan suatu pendekatan yang "hanya dapat memisahkan hasil-hasil dari linguistik, psikologi, sosiologi, etnologi, seperti yang ada, serta berusaha untuk mengkorelasi-kannya" (Hymes,1974:242). Akan tetapi, etnografi komunikasi merupakan suatu pendekatan yang berusaha untuk membuka kemungkinan-kemungkinan analitis yang baru (dengan menemukan jenis data dan permasalahan baru) dan mengajukan teori-teori yang baru.

Etnografi komunikasi berusaha untuk melakukan hal tersebut dengan menganalisis pola-pola komunikasi sebagai bagian dari pengetahuan budaya dan perilaku: pendapat ini berimplikasi pada pengakuan terhadap adanya keragaman komunikasi dan praktik komunikasi, (misalnya sesuai dengan relativitas budaya) serta fakta adanya keragaman praktik komunikasi itu merupakan bagian yang terpadu tentang apa yang kita ketahui dan kita lakukan sebagai anggota dari suatu budaya khusus.

\section{Fokus dan subfokus penelitian}

Berdasarkan uraian dalam latar belakang tersebut, maka fokus penelitian ini adalah interaksi komunikasi yang terjadi dalam dialog drama performance mahasiswa jurusan Bahasa Inggris di kelas pada kampus STIBA IEC Jakarta sebagai analisis wacana dengan pendekatan etnografi komunikasi yaitu menggunakan model SPEAKING GRID dari Hymes.

Jadi, masalah dalam penelitian adalah bagaimana pola komunikasi yang terjadi dalam dialog drama performance mahasiswa?

\section{Tujuan}

Sesuai dengan permasalahan yang akan dikaji sebagaimana dipaparkan sebelumnya, penelitian ini diarahkan untuk menemukan jawaban atas pertanyaan tersebut di atas yaitu:

Untuk mengetahui pola komunikasi yang terjadi dalam dialog drama performance mahasiswa di kelas jurusan Bahasa Inggris STIBA IEC Jakarta.

\section{KAJIAN TEORITIS}

\section{a. Konsep tentang Drama}

Pada mulanya, kata teater berawal dari bahasa yunani, yaitu teather, theatron (theathres) yang berarti gedung pertunjukan. Di yunany teater bermula dari kehidupan berpura-pura dan meniru suatu kehidupan.Kemunculan pertunjukan di yunani diilhami oleh pemujaan terhadap dewa dewa dan juga pada ritual olimpiade di coliseum. Penyebab lain adalah kejenuhan masyarakat dalam menjalani kehidupan. Pertunjukan diyunanai menjadi budaya di kalangan bangsawan atau raja-raja. Popularitas perkembangan kebudayaan di Yunany pada saat itu menjadikan istilah teater atau drama muncul, sejak saat itu mulailah menyebar ke Negara Negara di sekitar seperti Italia, Inggris yang pada masa kolonialisme dikembangkan di daerah jajahannya (Hariawan, 1988:24).

Secara bahasa, teater berarti “tontonan”. Dalam arti luas, teater adalah suatu pertunjukan untuk dapat disaksikan oleh banyak orang. Haryawan (1988:2) menyatakan bahwa teater dalam arti sempit adalah drama, kisah hidup kehidupan manusia yang diceritakan dalam pertunjukan dan disaksikan oleh banyak orang. Oleh karena itu drama termasuk gendre sastra, di mana sastra merpakan mimesis ( tiruan) yang memiliki kebenaran dan pengetahuan.

Akan tetapi, ketika merujuk lagi ke wacana yang lebih luas, ada perbedaan antara drama dan teater. Drama lebih tertuju pada kualitas komunikasi, situasi, action ( semua yang diperlihatkan dalam pementasan yang menimbulkan perhatian, kehebatan dan keteganagan penonton menyaksikan konflik ( Hariawan 1988:23). Berbeda dengan haryawan Hasanudin (1996:61)) mengemukakan bahwa drama adalah cerita atau tiruan perilaku manusia yang dipentaskan”. Teater dan drama dapat dibedakan kalau teater memiliki lahan yang luas dan dikategorikan pertunjukan,dan teater tidak terikat pada cerita atau tiruan perilaku manusia, sedangkan drama memiliki kekhususan sebagai salah satu genre sastra, darama dalam pengertianya membutuhkan persyaratan ketat untuk dapat dikatakan sebagai drama, secara prinsip drama memiliki struktur pembangn seperti penonton (audience), tempat ( stage), naskah (dialog), dan pemain (actor), dan kategori yang lain untuk dapat dikatakan sebagai drama adalah adanya gambar tentang kehidupan manusia dan didalam terdapat alur dan konflik.

Berdasarkan penjelasan tersebut, dapat disimpulkan bahwa drama sudah tentu merupakan bagian dari teater, dan teater belum tentu drama. Drama sebagai seni berlakon dapat disaksikan dalam pementasan 
dan pertunjukan untuk ditonton dengan memberikan ketegangan atau humor sampai pada titik tertentu. Jadi drama adalah merupakan cerita, perilaku manusia yang dipentaskan.

\section{b. Hakikat Dialog dalam Wacana}

Menurut (Herman 2015:24), Dialog sebagai wacana dicirikan oleh prinsip struktur fundamental yaitu interaktif dan interaksional. ini merupakan model percakapan pertukaran antara partisipan, percakapan yang berhubungan dengan percakapan lainnya dan tidak hanya semata-mata ungkapan verbal dari seseorang. Prinsip dialog telah dipahami dengan cara yang mendalam

Hal senada diungkapkan oleh Bakthi (1981:240), "dialogic interactiveness is omniscien and forms the basis of understanding itself, with social intersubjectivity taking priority over solo subjectivity in question of meaning

Selanjutnya, pendapat Herman, bahwa dialog menciptakan situasi yang dibangun oleh partisipan itu sendiri. ini termasuk pada percakapan lisan (spoken speech), bahwa kode linguistik yang digunakan dalam dialog diintegrasikan dengan kode lainnya dalam suatu pertunjukkan, seperti paralinguistik, kinesik, gestur, dan sebagainya.. Analisis unit linguistik cocok untuk dialog sebagai interaksional percakapan yaitu ujaran. Ujaran relevan untuk kajian 'language in use', kalimat dalam tata bahasa (Herman, 2015:25)

Dialog tidak hanya dipahami dengan teori yang dikaitkan dengan konsep kode, Bakhtin dalam Macovzki( 1981: 245) membandingkannya dalam dua hal, "Acontext is potentially unfinalized; a code must be finalized. a code is only a technical means of transmitting information, but it does not have cognitive, creative significance."

Menurut Cook (2004:178) Dialog adalah salah satu prinsip-prinsip struktural fundamental dari semua wacana, sama dengan wacana tulis maupun wacana lisan. Secara paradok, hal ini menjadi benar dalam wacana yang diciptakan oleh satu orang saja (monolog) seperti dalam wacana yang diciptakan oleh satu atau lebih (dialog). Beberapa tulisan teks yang paling awal dari budaya Barat eropa, dialog Socratik, menghadirkan seperti percakapan yang penulis modern tunjukkan sebagai monolog. mungkin beberapa pilihan dari praktek modern pada interaksi tatap muka: dosen di dalam kelas, wawancara pekerjaan, dan wawancara berita.

\section{Struktur Dialog}

Menurut Clark \& Clark (1997:179) bahwa percakapan dimulai dengan kalimat sederhana, seperti 'Hello', 'How are you', dan sebagainya. Setiap partisipan memulai percakapan dengan tujuan tertentu yang lebih khusus, begitupun sebaliknya bagi partisipan lain mempunyai tujuan yang sama. Permasalahan yang harus dipahami adalah bagaimana menyatukan tujuan. Dialog memiliki tiga struktur, antara lain :

\section{Giliran percakapan (Turn Talking)}

Jika partisipan yang terlibat dalam percakapan harus menyatukan tujuan, secara implisit mereka harus setuju dengan metode percakapan yang digunakan. Persyaratan utama untuk metode ini adalah:

- Setiap partisipan harus mempunyai kesempatan atau giliran untuk berbicara.

- Hanya satu orang yang harus berbicara dalam satu waktu (dia (partisipan lainnya) dapat mendengarkan).

- Perbedaan giliran harus jelas (efisien)

- Pesan pembicara dan isi yang pesan yang mereka sampaikan, tidak seharusnya salah diawal waktu percakapan.

- Ada teknik untuk memutuskan siapa yang harus bicara dan kapan.

Persyaratan tersebut merupakan sistem dalam gilran percakapan, agar percakapan berlangsung dari satu orang ke orang berikutnya dengan utuh. Masalah pengaturan giliran percakapan, menurut Sacks, Schegloff, dan Jefferson dalam Clark \& Clark (1997:243)

berdasarkan kebiasaan ada tiga aturan:

- Rule 1. The next turn goes to the person addreessed by the current speaker.

- Rule 2. The next turn goes to the person who speaks first.

- Rule 3. The next turn goes to the current speaker, if he resumes before anyone else speaks.

Ketiga aturan tersebut harus dipenuhi. Aturan pertama menjadi prioritas kemudian aturan kedua dan ketiga. Dan aturan kedua menjadi prioritas setelah itu baru aturan ketiga. Ketiga aturan tersebut harus digunakan dalam persyaratan percakapan. 


\section{Berpasangan (Adjacency Pairs)}

Proporsi signifikan dalam pertukaran dihubungkan oleh aturan pertama, dimana seorang pembicara menyampaikan kepada orang kedua, dan orang kedua menanggapinya. Kebersamaan dua pertukaran tersebut dilakukan bergantian secara berpasangan. Pasangan yang muncul bisa bervariasi, seperti:

- Pertanyaan-jawaban (question-answer)

- Sapaan-sapaan (greeting-greeting)

-Menawarkan-menolak (offer-acceptance/rejection)

-Tuduhan-pengakuan (assertion-acknowledgment)

-Permintaan-pemberian

(compliment-

acceptance/rejection)

Pujian-penerimaan (request-grant)

Berpasangan sendiri diatur dalam bagian yang lebih besar pada pelayanan tujuan global. Pasangan ini membantu untuk membuka percakapan, negosiasi, hubungan fakta, pertukaran topic, dan penutup percakapan. Hal ini menjadi penting ketika muncul kritik secara eksplisit dengan pembicara yang lain.

\section{Pembukaan Percakapan}

Untuk memulai percakapan, seseorang harus mendapatkan perhatian dari yang lain dan sinyal keinginan untuk percakapan, dan orang lain harus menunjukkan kesediaan untuk menjadi bagian. Hal ini bertujuan untuk urutan panggilan-jawaban (summons-answer sequence). Contoh: seseorang berkata 'hey, Bill,' dan yang lainnya menjawab, 'yes'.

\section{Penutupan Percakapan}

Masih menjadi hal yang rumit untuk proses penutupan percakapan. Untuk memberikan solusi terhadap kerumitan tersebut, menurut Sacks dan Schegloff, ada dua tahap utama dalam penutupan percakapan. Pertama, A dan B setuju untuk menutup percakapan. Kedua, mereka sesungguhnya menutup percakapan. Pada tahap pertama bahwa ini merupakan masalah yang paling sulit dan diselesaikan dengan penggunaan alat percakapan lainnya: pernyataan penutupan awal (pre-closing statement) dan tanggapan. Ketika hal ini pantas, pernyataan tersebut diawali dengan bagian penutupan percakapan, yang diakhiri dengan pertukaran perhentian. klasik, seperti 'Goodbye', sekali lagi bahwa berpasangan memiliki peranan utama agar percakapan dapat berlangsung dengan lancar.

\section{b. Hakikat Etnografi Komunikasi}

Menurut Hymes dalam scriffin (1972 :138) bahwa etnografi komunikasi dikembangkan oleh Hymes dalam suatu makalah berseri yang ditulis pada tahun 1960-an dan 1970-an (banyak yang dikoleksi dalam karyanya tahun 1974 Foundation in Sociolingitistics: An Ethnographic Approach), akar dari pendekatan ini ber $\neg$ orientasi pada gerakan Edward Sapir yaitu meninggalkan studi tentang bentuk dan isi sosiokultural sebagai "produk" ke arah studi bentuk dan isi sosiokultural sebagai "proses".

Berbeda dengan Hymes, Gumperz menekankan pada analisis penggunaan bahasa dalam situasi budaya yang berlaku pada masyarakat. Menurut Hymes dalam Scriffin (1978:139) bahwa etnografi komunikasi membentuk suatu kerangka kerja yang terpadu, di mana komunikasi mempunyai suatu KAJIAN dalam studi-studi antropologis dan linguistik. Hymes mengusulkan bahwa ilmu pengetahuan tentang komunikasi memusatkan perhatian pada kompetensi: pengetahuan yang mengatur fungsi tata bahasa yang tepat. Pengetahuan tentang aturan-aturan bahasa secara abstrak dimasukkan ke dalam kompetensi komunikatif. Tetapi, juga memasukkan kemampuan untuk menggunakan bahasa dalam situasi-situasi kehidupan sehari-hari secara konkret: ke-mampuan untuk berpartisipasi dalam percakapan, untuk berbelanja di toko, untuk mewawancarai (dan diwawancarai), untuk sebuah pekerjaan, untuk berdoa, melucu, membantah, menggoda, mengingatkan, dan bahkan untuk mengetahui kapan harus diam.

Menurut Wardhaugh (2006: ), “An ethnography of a communicative event is a description of all the factors that are relevant in understanding how that particular communicative event achieves its objectives. For convenience, Hymes uses the word SPEAKING as an acronym for the various factors he deems to be relevant".

Jadi, dalam kajian etnografi komunikasi memfokuskan kajian pada pertuturan bahasa suatu kelompok masyarakat. Dengan kata lain bahwa dalam etnografi tentang bahasa sebagai alat komunikasi difokuskan pada pemakaian bahasa dalam pertuturan atau lebih lagi. Etnografi komunikasi merupakan keseluruhan deskripsi dari faktor-faktor relevan yang memahami bagaimana komunikasi mencapai objek.

d. Metodologi: Etik Alur/Grid dalam Etnografi. 
Para ahli etnografi komunikasi menganalisis polapola komunikatif dengan menggunakan metode observasi partisipan: suatu tujuan penting adalah untuk mempelajari apa yang diketahui oleh para anggota dari budaya tentang bagaimana "membuat makna (sense)" di luar pengalaman dan bagaimana mereka mengkomunikasikan interpretasi-interpretasi tersebut. Untuk tujuan ini Hymes (1972 :141) mengusulkan suatu metodologi di mana untuk menemukan "apa yang tergolong" sebagai peristiwa komunikatif. Metodologi tersebut berdasarkan pada perbedaan antara emic dan etic.

Para ahli bahasa mengkaji sistem bunyi dari suatu bahasa yang tidak terkenal berusaha untuk mendapatkan pola- $\neg$ pola fonemik (yaitu bunyi apa yang "bermakna" dalam bahasa khusus) dengan bantuan suatu klasifikasi fonetik (yaitu bunyi apa yang secara fisik memungkinkan). Demikian juga, kita dapat memperoleh unit-unit komunikatif dengan bantuan dari suatu sistem klasifikasi yang membagibagi secara teliti komunikasi ke dalam komponenkomponen yang mungkin secara potensial terbentuk. Selanjutnya, kita juga dapat memperoleh pola-pola komunikatif (yaitu inventarisasi tentang peristiwa yang membedakannya secara sistematis) yang dibentuk dari keterkaitan di antara komponenkomponen tersebut.

Klasifikasi kisi-kisi yang diajukan Hymes dalam Deborah diketahui sebagai grid SPEAKING: masing-masing huruf merupakan sebuah singkatan untuk sebuah komponen komunikasi yang mungkin berbeda. Berikut adalah penjabaran dari SPEAKING Grid :

S setting (latar) keadaan fisik

Scene (suasana) definisi subjektif dari suatu peristiwa

$\mathbf{P}$ participants (peserta) pembicara/pengirim/alamat

Pengirim/mitra/tutur/penerima/audien/alamat yang dikirimi

E ends (tujuan) tujuan-tujuan dan sasaran-saran hasil-hasil

A act sequence (urutan tindakan) bentuk pesan dan isi

K key (kunci) nada, cara

I Instrumentalities (sarana) aluran (verbal, nonverbal, fisik) bentuk-bentuktuturan yang diambil dari repertoar masyarakat

$\mathbf{N}$ norms of interaction and interpretation (norna interaksi dan interpretasi) Kesopanan tertentu yang digunakan dalam berbicara interpretasi tentang norma-norma di dalam sistem kepercayaan kultural

G genre (jenis) kategori-kategori tekstual

Grid SPEAKING dapat digunakan untuk menemukan suatu tak-sonomi lokal (yaitu relatif secara kultural) tentang "unit-unit" komuni $\neg$ katif yang "dalam cara yang dapat diketahui terikat atau terpadu" . Unit seperti itu yang terbesar adalah situasi tutur: kesempatan sosial di mana tuturan bisa terjadi (misalnya makanan). Meskipun situasi-situasi tutur bisa memberikan setting di mana tuturan terjadi, situasi-situasi itu sendiri tidak diatur oleh seperangkat aturan-aturan tunggal. Unit berikutnya adalah peristiwa tutur: "aktivitas- $\neg$ aktivitas, atau aspek-aspek dari aktivitas-aktivitas, yang secara langsung diatur oleh norma-norma tindak tutur". Unit yang terkecil adalah tindak tutur: meskipun Hymes tidak menentukan hal ini secara eksplisit, contoh-contoh ini terrnasuk tindakan-tindakan yang dapat didefinisikan melalui daya ilokusi.

Meskipun wacana adalah penting untuk semua unit, ini cenderung merupakan tingkatan tindak tutur yang paling fundamental pada bagian wacana tersebut, secara bergiliran manajemen tentang wacana: "Wacana dapat dipandang dalam hal-hal tindakantindakan secara sin-tagmatis dan paradigmatis: yaitu, keduanya sebagai suatu urutan tindak tutur dan dalam kelas-kelas tentang tindak tutur di antara pilihan-pilihan yang telah dibuat pada poin tertentu". Akhirnya, unit-unit yang lebih besar dalam keadaan yang mengelilingi yang lebih kecil: suatu pesta adalah suatu situasi tutur; suatu per-cakapan selama pesta adalah suatu peristiwa tutur; suatu gurauan di dalam percakapan adalah suatu tindak tutur.

\section{METODOLOGI PENELITIAN}

Objek penelitian ini adalah dialog dalam drama kelas pada mata kuliah Drama Performace pada jurusan bahasa Inggris di STIBA I-EC Jakarta dengan judul "SNOW WHITE". Peneliti hanya menggunakan data dialog scene 3 untuk analisis interaksi komunikasi. Metode penelitian yang digunakan adalah analisis isi dengan model SPEAKING GRID dari Hymes.

\section{HASIL DAN PEMBAHASAN}

Pada bagian ini mengetengahkan hasil analisis. Hasil analisis di ambil dari keseluruhan data yang berupa dialog dalam drama performance SCENE 1-3.

Peneliti akan memaparkankan setiap komponen dari SPEAKING kedalam dialog drama performance 
mahasiswa di kelas sebagaimana yang terdapat dalam analisis SPEAKING Grid. Berikut ini adalah penjabaran lebih luas dari setiap komponen terhadap dialog yang ada di scene 1 dalam pementasan drama mahaiswa yang berjudul "SNOW WHITE"

Tabel 1. Komponen dialog scene 1

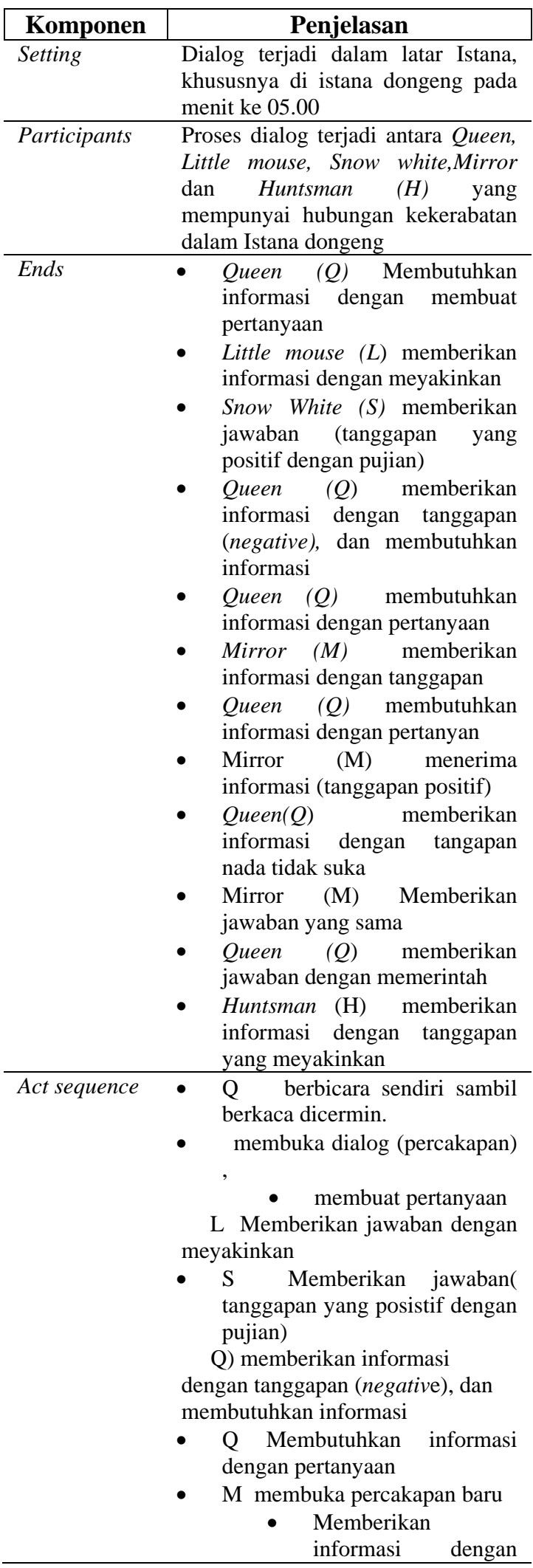

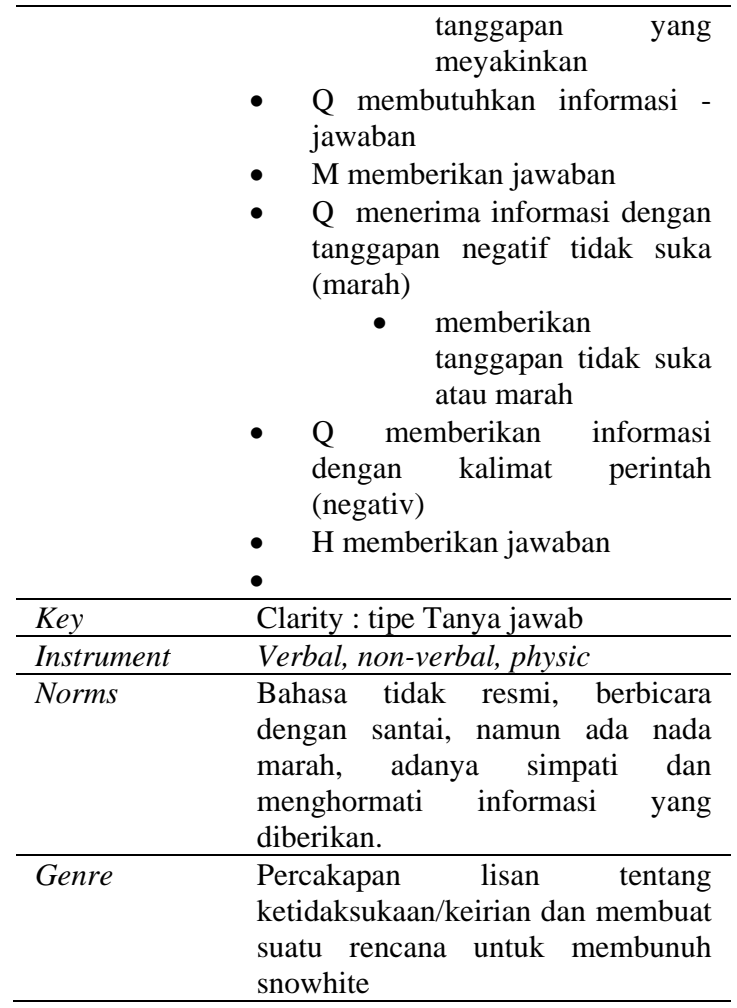

Drama performance di atas diawali dengan seseorang ratu ibu tirinya Snow White (Queen) yang berbicara sendiri karena iri dengan kecantikan Snow White dan dia sangat heran mengapa orang lain menyukai snow white padahal menurut queen ia tidak secantik Queen. Dalam Hal ini queen membutuhkan informasi dengan bertanya keheranan. , hal ini dapat diketahui dari tuturan" Why does everyone like her? She is not as beautiful as me. Kemudian di tanggapi oleh Little mouse yang menanggapi percakapan tersebut dengan menyatakan bahwa queen juga cantik dan memiliki kecantikan yang sama, ini dapat dilihat dari tuturanya" You are beautiful, snow white and you have a beautiful mind,too. Disini terjadi percakapan dan tanggapan positif, lalu hadirlah Snow white menanggapi percakapan tersebut dengan mengucapkan terimakasih pada little mouse terhadap pujian yang dilontarkan padanya,dan tuturan tersebut "Thanks little mouse. You are kind"

Namun tanggapan positive yang dilontarkan oleh snow white membuat queen marah dan menyatakan membenci snow white dengan tuturanya"I hate her". Percakapan dilanjutkan dengan queen yang bertanya pada Mirror tentang siapa yang paling cantik didunia ini, hal tersebut dapat dilihat dari tuturanya,"Mirror mirror on the wall,who is the fairest of them all. lalu dijawab oleh mirror yang paling cantik didunia ini adalah Queen, hal tersebut dapat dilihat dari dialognya" you, queen". You are the fairest of them all. Setiap hari mirror selalu menanggapinya dengan 
Haryawan. Dramaturgi. Bandung: PT. Remaja Rosakarya. 1988.

Hasanudin,WS. Drama karya dalam dua dimensi. Bandung. 1996

Hymes, D. H. "Foundations in Sociolinguistics: An Ethnographic” Approach.” Philadelphia: University of Pennsylvania Press. 1974

Hymes, D. H. “On Communicative Competence.” 1972. In Pride and Holmes Macovski, Michael. "Dialogue and Critical Discourse Language, Culture, Critical Theory.” United States of America:

Schiffrin, Deborah. "Approaches to Discourse." Oxford: Blackwell Publishers Inc.ford University Press. 1995

Wardhaugh, Ronald. "An Introduction to Sociolinguistics Fofth Edition.” UK: Blackwell Publishing. 2006

\section{Biodata Penulis}

Dr. Sri Arfani, S.S, M.Pd. Memulai karier mengajar pada tahun 1998 di LPIA cikarang dan Bekasi, pada saat itu beliau dipercayakan menjadi Koordinator bidang akademik Bahasa Inggris. Pada tahun 2004 beliau bergabung menjadi dosen tetap di ABA BSI Jakarta hinggga sekarang. Beliau juga telah berpengalaman menjadi pembicara di beberapa seminar internasional dan nasional, dan telah menghasilkan beberapa karya ilmiah.Saat ini beliau telah selesai melanjutkan studi S3 di Universitas Negeri Jakarta di jurusan Pendidikan Bahasa dengan kosentrasi pendidikan bahasa Inggris.
Appendix

Scene 1( in the castle)

Narator

Once upon a time there was a king had a daughter with very black hair. She was sweet and pretty, and everybody loved her. She was called Snow White. The mother of the sweet little princes died and her father got married again with a beautiful but wicked queen. She hated her pretty stepdaughter, snow white.

Queen : ( talking to her self) Why does everyone like her? She is not as beautiful as me.

Little mouse : You are beautiful, snow white and you have a beautiful mind,too.

Snow White : Thanks Little mouse. You are kind.

Queen : (growling) I hate her!

Queen : Mirror,mirror on the wall, who is the fairest of them all?

Mirror : You, queen. You are the fairest of them all.

Narator

Everyday The mirror answered with the same answer. But one day it answered.

Queen : Mirror,mirror on the wal, who is the fairest of them all?

Mirror : Snow White

Queen : ( Screaming) No! I will ask you again. Mirror,mirror on the wall, who is the fairest of them all?

Mirror : Snow White. Snow White is the fairest of them all.

Narator

The queen was very angry. She ordered her huntsman to kill Snow White.

Queen : Argggh........Snow White how dare you to compete my beauty! Huntsman, huntsman, go and kill Snow White!

Huntsman : Yes, your Majesty. 